\title{
The Policies of Social Innovation: A Cross-National Analysis
}

\section{Gorgi Krlev', Torbjörn Einarsson², Filip Wijkström², Lea Heyer ${ }^{3}$, and Georg Mildenberger'}

\begin{abstract}
This article deals with the policy discourse on social innovation at the European Union (EU) level as well as across nine European countries. We perform an exploratory analysis of relevant policy documents focusing on articulated policy authority, suggested actors, and key outcomes of social innovation. We also conduct an explanatory testing of the applicability of the varieties of capitalism as a traditional innovation classification system to social innovation. We find that the policy discourse across Europe lacks systemization and that EU agendas are only incompletely replicated at the individual country level. We also find that social innovation policies largely defy the principles governing traditional innovation policy regimes, which necessitates new or revised classification frames.
\end{abstract}

\section{Keywords}

social innovation, policy, cross-national analysis

\section{Introduction}

Social innovation, sustainability, and well-being have become a priority area in European Union (EU) policies (Dax \& Fischer, 2017), with more than a dozen major research projects on social innovation funded by the European Commission at present. Research has not kept pace with this development in terms of analyzing what expectations are held about the promotion of social innovation or who the main actors are

\footnotetext{
IUniversity of Heidelberg, Germany

${ }^{2}$ Stockholm School of Economics, Sweden

${ }^{3}$ University of Hildesheim, Germany

Corresponding Author:

Gorgi Krlev, Centre for Social Investment, University of Heidelberg, Bergheimer Strasse 58, 69II5

Heidelberg, Germany.

Email: gorgi.krlev@csi.uni-heidelberg.de
} 
supposed to be-and whether the focus on the EU level is effectively mirrored in national-level policies. By relating to "agenda setting" (Rogers \& Dearing, 1988; Walgrave \& van Aelst, 2006) by policymakers, we want to develop further the few previous attempts made to pin down the nexus between policy and social innovation, which have hitherto primarily been restricted to developing countries (Nicholls, 2013; Rao-Nicholson, Vorley, \& Khan, 2017). In this article, we analyze whether and in which ways social innovation policies defy the principles governing traditional innovation policy regimes and whether this line of policy work might necessitate a new or at least revised classification.

First, we perform an in-depth analysis of a number of central policy documents in each of nine European countries and at the EU level to reveal peculiarities in the respective policy discourses as regards social innovation. Our investigation is based on a tailored methodology that combines a quantitative and a qualitative approach. Our four guiding questions for this part of the research are as follows: (a) What do social innovations generally refer to in the policy documents? (b) How do they relate to other types of innovation? (c) What outcome is expected from social innovation? (d) Who are the main innovation actors supposed to be? The qualitative analysis reveals a huge degree of cross-national variation regarding the different ambitions and hopes for social innovation, who the involved actors should be, and the actual policy levels affected. The latter form a fuzzy set of elements and relations that could hardly be compared across countries. This points to the need for systematization and more informed policy dialogue at both the national and the EU level. The quantitative analysis in turn uncovers the main political actors propelling social innovation, among which we most often find the ministries of the economy, labor, and social affairs and a number of related national-level bodies. "Social services" and "health care" are identified as the most prominent fields where social innovations are expected to happen, according to our policy analysis.

Second, we bring together social innovation and the varieties of capitalism (VoC) approach (Hall \& Soskice, 2001) as one of, if not, the most dominant views conceptualizing innovation regimes by variance in the properties of national political economies. In a separate section dedicated to research questions, we develop and test three propositions on likely differences in social innovation policies in various countries, depending on their classification according the VoC approach. Based on a typology of our nine European countries, we find mixed evidence on whether social innovation is more oriented at social policy goals in coordinated market economy (CME) countries and more related to technological innovation policy in liberal market economy (LME) countries. We also find counter-evidence for the supposition that civic involvement in social innovation will be more favored in CME country policies than in LME country policies. Finally, and this time in better accordance with the assumptions behind the VoC approach, we find that social innovation policies in CME countries address multiple levels of locality, whereas those in LME countries tend to focus more on nationallevel issues.

Our analysis suggests that social innovation policy deviates from traditional innovation policy regimes. In contrast to technological innovation, for example, policy 
authority is dispersed across a variety of ministries. And in deviation from classifications within VoC, we identify a selective combination of elements, for instance, a national-level policy focus and the stimulation of civic engagement at the local level. We contribute to the main of nonprofit studies in two ways: First, we outline the links between nonprofits and social innovation as prevalent in concurrent policies. This extends previous and more narrowly focused examinations of nonprofit innovation (Lurtz \& Kreutzer, 2017; Messeghem, Bakkali, Sammut, \& Swalhi, 2018; Osborne, 2013). It can include collaborative innovation (Crosby, 't Hart, \& Torfing, 2016), "prosocial" open innovation (Bogers, Chesbrough, \& Moedas, 2018), systems innovation (Schot \& Steinmueller, 2018), and innovation policy addressing grand challenges (Kuhlmann \& Rip, 2018). It extends as far as the new policy priority on missiondriven innovation (Mazzucato, 2018). Second, we examine agenda setting promoted by policymakers as regards core challenges and expectations in major social policy areas. These policy areas are populated substantially by nonprofit organizations and the expectations held within policymaking and regulative control thus critically affect nonprofit strategies for operating in them (Bryson, 2018). Therefore, promoting innovation is placed in between the usual focus on civicness and market orientation (Kim, 2016) and could be seen as a new "capacity" to be developed (Despard, 2016).

\section{The Meaning of Policy Analysis}

In contrast to "traditional" foci in the study of contextual influences on social phenomena, such as institutional settings (North, 1990), our focus on policies offers a more targeted framework. It comprises "institutions in becoming" because policymaking is often a pre-stage to institution building (Krlev, Bund, \& Mildenberger, 2014). By conducting a policy analysis, we can look at specific factors that might stimulate or hinder social innovation in various policy regimes. This opens up potential links between social innovation and other, more established policy areas such as technological innovation.

Like social innovation (see Ayob, Teasdale, \& Fagan, 2016, for a review of the evolution of its meaning), "policy analysis" itself is not a clear-cut phenomenon or approach. Although most researchers in public policy analysis are positioned in the tradition of discourse theories such as those developed by Foucault, Laclau, Mouffe, or Bourdieu, there is no one canonical method of policy analysis (Hewitt, 2009). Only in recent years has a "professionalization of public policy studies" occurred (Bozeman, 2013, p. 171). Bozeman argues that the field of policy studies is still fragmented, regarding both the disciplinary background of its scholars and the content of the policies analyzed. He explains this with a strong practical orientation in policy studies, which made scholars pay little attention to theory building. Gradually, the "classical" theoretical works in policy research ranging from punctuated equilibrium(Baumgartner, 2014), to policy streams (Kingdon, 1995), to advocacy coalition frameworks (Sabatier \& Jenkins-Smith, 1993) are not only revised, but research comes to inquire "whether this particular kind of thinking about public policy has come to the end of its line of development, and whether there is potential for a synthesis and further innovation" 
(John, 2003, p. 482). Presenting novel theoretically informed frameworks for policy analysis such as the one developed by Stone and Sandfort (2009) to benefit nonprofit studies. Policy analysis is becoming more compatible with other fields of research, such as organization theory.

Despite partly drawing on traditional schools of discourse theory, policy analysis must not be confused with "political discourse analysis" which would comprise "interand multi-disciplinary research that focuses on the linguistic and discursive dimensions of political text and talk and on the political nature of discursive practice" (Dunmire, 2012, p. 735). Rather, policy analysis focuses on ideas and framing to analyze ideational processes' impact on policy change (Béland, 2009, 2016). Policy analysis draws on diverse schools of discourse theory and comes in the form of semantic policy analysis (Howarth \& Torfing, 2005), category analysis (Yanow, 1996, 2009), or pragmatic policy analysis (Hajer, 2003). It contains a focus on identifying policy paradigms, ideas, and dynamics (e.g., Daigneault, 2014). Thus, policy analysis may be understood as a discourse analysis that draws on policy documents as primary sources of material to understand governance, policies, and policymaking. It is therefore apt to "reveal 'the how' of these processes and practices" (Atkinson, Terizakis, \& Zimmermann, 2010, p. 2) and the ways in which legitimacy is accorded to different forms of knowledge in policymaking.

\section{Why Focus on Policies in Relation to Social Innovation? And How to Do It?}

The recent application of policy analysis in fields relevant to our research provides us with quite a diverse picture. Research in the area of social reform, innovation, and social innovation seems to focus on three aspects: (a) examining policy as an innovation in itself, (b) the implications, and (c) the effects of policies and/or the ideas and concepts that underlie such policies.

Instances of the study of "policies as social innovation" (Edmiston, 2015) are least prevalent. Exemplary of such a perspective is the study by Lacomba, Boni, Cloquell, and Soledad (2015), which examines the involvement of immigrant associations in the development of their countries of origin, an innovative approach in regional policymaking in Spain.

In contrast, the second area from above, namely, the practical implications of policies, is by far the most common. Field-based studies like the one carried out by Fotaki (2010), asking "Why policies fail so often" in the field of health policymaking, or the one by $\mathrm{Haß}$ and Serrano-Velarde (2015) examining the effects of government policy on volunteering traditions, are typical of this approach. Other research has been performed with a geographic focus and has looked at the implications of welfare reforms on trust in the third sector in Britain (Milbourne \& Cushman, 2013), competitive bidding as a governmental policy instrument in Hong Kong (Wen \& Chong, 2014), the characteristics and impact of different institutional environments in nonprofit welfare provision in Denmark (Thøgersen, 2015), and partnership-oriented public policy in 
Quebec (Jett \& Vaillancourt, 2011). Finally, some research is placed within institutional or organizational theory more broadly, for instance, the analysis of governmentvoluntary sector "compacts" as a recent policy instrument (Reuter, Wijkström, \& von Essen, 2012), or that of strategic plans and their effects on power allocations within city organizations (Vaara, Sorsa, \& Palli, 2010).

All of these studies, regardless of their focus, pay tribute to the fact that policies' original intention, design, and outcomes are often not congruent and make policies "collide with and contradict one another" (Atkinson et al., 2010, p. 7). We are still far from a position from which to provide such an analysis because European social innovation policy is in a nascent and formative stage. What we can do is trace crossnational agendas and identify commonalities or differences between the policy discourse on social innovation and that in more traditional policy fields.

It is therefore the last of the three areas that is ideologically closest to our own aims. It is represented by policy analysis that seeks to reveal the ideas that underlie reforms and political measures and thus contributes to an understanding of the discourses shaping political decisions. Existing studies span the issue of civicness in the governance of social services (Enjolras, 2009) or transformations in the provision of social service and trends of field convergence (Henriksen, Smith, \& Zimmer, 2012). With their study on the EU's social innovation discourse, Fougère, Segercrantz, and Seeck (2017) provide us with one of the most closely related studies. Their specific focus lies on debating the supposed neoliberal reasoning behind promoting social innovation. Fougère et al.'s work resonates with the "highly politicized nature" of the social innovation discourse (Sinclair \& Baglioni, 2014, p. 474; also Baglioni \& Sinclair, 2018; Sinclair, Mazzei, Baglioni, \& Roy, 2018). It also relates to the claim that social innovation is a "contested policy space sitting across the grand narratives of contemporary society," an observation which comes with the urge that we need to better understand "the competing paradigms and forces that shape public policymaking at the strategic level" (Terstriep \& Totterdill, 2014, p. 17). In other words, we need to better understand how policies may and do shape the field of social innovation, which is the aim of this article.

As most policies are still at a distance from being institutionalized, we are only able to provide a generic cross-national overview of shared themes and engaged policy bodies, and how they view social innovation or intend to promote it. In that sense, we act in the tradition of agenda setting theory (Rogers \& Dearing, 1988), which originated in political science but has mostly been promoted in communication research, in particular with a view on how mass media shape public discourse and opinion. The role of policymakers in this context has gained new interest (Walgrave \& van Aelst, 2006), yet policymakers are treated as one of several constituents in promoting an agenda.

Our approach is different in that we take policymakers as the central shapers of public perceptions, policy action, and communication surrounding a new phenomenon as the medial device by which political intentions can be judged. We aim at better understanding which policy bodies are seen as responsible for social innovation crossnationally, what social innovation means to them, what they demand from it, and how 
these actors would expect the phenomena to be promoted. First, in a generic fashion, we screen the scene of social innovation policy as regards actors, fields, and goals (exploratory analysis). Second, we test whether country classifications of social innovation policies can be performed in line with the implications from technological innovation policy (explanatory analysis).

\section{Research Questions and Propositions}

The exploratory part of our policy analysis was meant to map and compare the expectations and supposed actors of social innovation across Europe. The explanatory testing we performed related to whether patterns in social innovation policy could be spotted that are similar to classifications of a country's capacity to innovate technologically. Related research comprises, for example, the comparison of innovation governance in democratic versus authoritarian regimes (He, 2016; Stier, 2015), differences between industrialized versus developing countries (Casadella \& Uzunidis, 2017), or within-country variation across regions and policy levels (Balme \& Ye, 2014; Prange, 2008).

We chose the "varieties of capitalism" approach (Hall \& Soskice, 2001) as our point of anchorage as it is clearly the most discussed and developed theoretical approach to systems of innovation and innovation governance (Höpner \& Schäfer, 2012 , p. 174). The VoC approach represents a classification which is based on a wide range of empirical observations (Höpner \& Schäfer, 2012). We suppose that aggregate policy traditions such as those typical for LMEs, CMEs, and those in between (Schneider \& Paunescu, 2012) are part of the macrostructures that would also shape and govern the formation of social innovation policies. We further assume that policy traditions would influence policymakers' perspective on innovation in a country more generally, including social innovation, and developed three propositions on how social innovation policies would materialize within the classification system. The propositions focus on policy objectives (social vs. technological orientation), direction in the policy approach promoting social innovation (grassroots or top-down involvement), and the governance levels at which the analyzed policies are primarily located (local vs. national level).

Given "innovation-driven growth approaches" (Ramstad, 2009, p. 533; also Fligstein, 2006) in contemporary Western economies and the strong influence of market actors in LMEs, we expect social innovation policies in such countries to be directed by the traditions of technological innovation policies. Social innovation, however, generally relates more strongly to social problems and challenges, moderating social productivity or performance. It is less driven by the profit motive and therefore often more dependent on financial support (e.g., Pol \& Ville, 2009). Such an approach will supposedly more likely be driven by public or government actors, which are more dominant in CMEs. We therefore assume that in these countries social innovation policies would be more social policy directed. Our first proposition is thus as follows: 
Proposition 1: In LME countries, social innovation policy will be placed within the context of technological innovation, whereas in CME countries social innovation policy will have a stronger relation to social policy and its objectives.

We also considered the degree of participation supported by policymakers in the different regime types. Because LME countries are more willing to accept the emergence of strong directional forces as a result of market competition, ${ }^{1}$ we also expect social innovations to be strongly controlled and pushed by those in charge. Such directional influences would make social innovation policies follow a top-down logic. In CME countries, on the contrary, by way of their conception, we expect to find a greater degree of coordinated involvement, which will not only require more effortful bargaining, leading to developments that need more time to evolve, but also promote civic engagement. ${ }^{2}$ We therefore expect policy approaches to social innovation to be more participative and focused on the involvement of citizens, activists, or other groups in the latter countries. We formulate the following proposition:

Proposition 2: In LME countries, social innovation policy will follow top-down logic, whereas in CME countries civic participation processes, that is, bottom-up logic, will be more pronounced.

Following the same line of reasoning, third we propose that the main level affected by social innovation policies will vary depending on the degree of state or market influence in a given country. We expect social innovation policies in CME countries to particularly address multiple levels, including local structures. This expectation is informed by previous research on social innovation emphasizing the importance of regional contexts in favoring connectivity and openness as crucial elements for grassroots innovation (e.g., Asheim, Lawon Smith, \& Oughton, 2011; The Young Foundation, 2012). In resonance with their suggested tendency to develop and implement top-down innovation policy approaches, LME countries are expected to focus on the national level. We therefore posit the following:

Proposition 3: Social innovation policies in LME countries will focus on the national level, whereas policies in CME countries will address multiple levels, including the local level.

\section{Method}

In a first step, we identified between five and nine policy documents of relevance at the EU level as well as on that of nine European countries that were part of the ITSSOIN (Impact of the Third Sector as Social Innovation) project: the Czech Republic, Denmark, France, Germany, Italy, the Netherlands, Spain, Sweden, and the United Kingdom. All documents related to social innovation matter. Overall, a sample of 53 documents originating in the years 2001 to 2014 was analyzed (six documents at 
the EU level and 47 documents in total at the country level). To allow for comparison across countries, the number of policy documents was limited to five major publications of 30 to 50 pages per document per country. Relevant policy documents on the country level were selected by locally well-embedded research teams, based on insights on (social) innovation policy at the EU level. These were derived from an initial screening of the most well-known and relevant policy publications such as the "Guide to Social Innovation" (European Commission, 2013; see also the analysis below). In addition to the angle of innovation, we also looked at sector-specific reports as to the involvement of particular types of actors and the roles they were to play in social innovation. While considering all three sectors-public sector, commercial actors, and civil society-some preference was given to reports relating to the third sector or civil society in particular due to the supposed vicinity of such actors to social innovation (Kendall, 2009). ${ }^{3}$

We focused on key policy documents as an embodiment of the national positioning as regards social innovation. This is also why we refer to countries rather than documents in the classification of countries in our analysis. The types of policy documents that we included in our analysis were, for example, Legislations, government documents (statements from ministries or national public administration bodies, e.g., outlining a policy strategy), press releases (issued by ministries or administration), proposals to parliament/elected bodies (made by third party, e.g., ministers, official advisory boards, private lobby groups), instructions to departments/bodies/agencies, official statements/declarations of intent, documentation of a parliamentary debate, or government-sponsored conference reports dedicated to themes of relevance.

The policy levels of the many actors publishing reports include: national, federal state/regional, and local authorities, as well as cross-cutting institutional actors, for instance, those specialized in social entrepreneurship. It is important to mention here that we had to distinguish between documents using the term "social innovation" directly and others that only referred to the concept, for instance, by referring to "innovation in the social sphere." In the following, we will not go into great detail regarding this distinction, but we respected it throughout our analysis. Where available, we gave priority to such texts that explicitly addressed social innovation.

After document identification and selection, national research teams performed the analysis guided by a jointly developed coding framework laid out below, and using qualitative data analysis software such as MaxQDA, Atlas.ti, or NVivo. Researchers were required to cross-code $10 \%$ of the items to measure intercoder reliability, which lay well above $75 \%$. Coders were also asked to keep an individual log book where all doubts and ambiguities were addressed and then settled by means of consensus among the involved researchers. The content analysis of documents was guided by a joint code book containing 25 predefined items of relevance - of which some are outlined below-as well as instructions for the coding procedure allowing for an in-depth and thus flexible, but also standardized, analysis of country-specific policies (see Anheier et al., 2015, for more details). Our policy analysis has thus been conducted in the style of a "structured content analysis" (Mayring, 2007; Schreier, 2013). 
For some of the core items, the qualitative codes gathered in the analytic software were transformed to a classification on a five-point scale ranging from $1=$ the aspect was not present at all to $5=$ the aspect was very prominent. These transformations were carried out in content-specific ways. The "prominence of social innovation as an overall theme" was, for instance, judged by the number of uses of the specific term within the document. The "relation of social innovation to technological innovation" was deducted in a more indirect way. The option "No relation" was, for example, chosen by the coders when a single type of innovation was discussed in the document in isolation. The categories "the relation of social innovation to institutional settings" or "the connection between the countries" policies and the EU agenda" were assessed in much the same way.

Other items were structured by a range of selection options. Those options used for the topic "main policy level affected by/focusing on social innovation" ranged from national, to regional, to local. The question "target fields of social outcomes," on the contrary, specified a number of concrete fields of activity spanning from arts and culture to work integration. For the item "main desired outcomes of social innovation," some such outcomes were specified in an exemplary fashion, explicitly naming, for instance, social innovation as a motor for economic growth, or social cohesion. Both the number of and types of items themselves and the coding options were kept open to additions throughout the process so as to enable the inclusion of new categories throughout the analysis. The information was condensed into a cross-national analysis of major themes and subjects, the results of which we present in the following.

\section{Exploratory Analysis: Policy perspectives and Country Profiles}

The analysis of policy documents revealed that policymakers approach the topic of social innovation from a range of different angles or perspectives. Our analysis indicates that European policymakers in general have quite general and rather vague expectations and also link or relate social innovation to a vast number of different subjects or matters. Apart from this overall conclusion from our survey, it is therefore difficult to generalize the results. Nevertheless, we did identify some interesting trends and tendencies in the material. As a grounding and reflective device, we first provide a short summary of patterns identified in policy perspectives at the EU level. We then proceed accordingly with the analysis of country policies.

\section{Policy Perspectives at the EU Level}

European policies on social innovation are mainly focusing on authorities concerned with economy, labor, and social affairs and thus exhibit a rather narrow scope. Regarding thematic fields instead, no single prioritization or thematic emphasis was identified. Foci are equally distributed and address fields ranging from work integration, health, and social services to community development and environmental 
Table I. Policy Authority Over Social Innovation.

\begin{tabular}{|c|c|c|}
\hline & \multicolumn{2}{|c|}{ Policy authority } \\
\hline & Focused policy authority & Dispersed policy authority \\
\hline Responsible policy bodies & Economy, labor, social affairs & $\begin{array}{l}\text { Wider range of ministries/policy } \\
\text { areas }\end{array}$ \\
\hline Countries & $\begin{array}{l}\text { Czech Republic, France, } \\
\text { Germany, Italy, Spain }\end{array}$ & $\begin{array}{l}\text { Denmark, Sweden, The } \\
\text { Netherlands, The United } \\
\text { Kingdom }\end{array}$ \\
\hline
\end{tabular}

sustainability. In general, we found a much stronger focus on social innovation at the EU level than at national levels, and the social innovation discourse of the EU related to technological innovation and social policy alike. The suggested outcomes of social innovation are also of an economic as well as community-oriented nature, and the policy levels relevant to governing social innovation range from the EU to the local level. EU policies only weakly relate social innovation to the market, the state, or the third sector, but small and new organizations were framed as being particularly innovative. Civic action within social innovation was pronounced merely to a "medium" degree.

\section{Policy Authority, Target Fields, and Main Outcomes at the Country Level}

Looking first at the bodies which are involved with innovation policy, a range of ministries from different areas were found in the material. The most prominent are national-level ministries of economy, labor, and social affairs. However, we find two rather distinct clusters of countries in our sample: one where policy authority over social innovation is focused on the latter three ministries or policy areas, and one where authority over the subject is dispersed across a wider array of ministries and policy areas, including the ministries of culture, environment, or family. These two clusters are summarized in Table 1.

The thematic or field-related scope in social innovation policies shows some more variation. "Social services" and "health care" have emerged from the analysis as the fields most strongly promoted across countries. "Work integration," "community development," and "environmental sustainability" followed suit. When looking at these five fields, we can identify two clusters of countries, one where service-oriented fields are more prominent and one where advocacy-oriented fields are in the foreground (see Table 2). There is one exception to this classification, which is Italy, where no prioritization of fields of activity occurs.

As shown in Table 3 on suggested and sought-after outcomes of social innovation, we identified three dominant discourses: Some countries focus on social innovation in the context of volunteering and civic engagement (Denmark and Spain). Their policy discourse is marked by an orientation toward solidarity and/or social cohesion. Yet, economic 
Table 2. Target Fields of Social Innovation Policy.

\begin{tabular}{llll}
\hline & \multicolumn{3}{c}{ Character of policy } \\
\cline { 2 - 4 } & Service oriented & Advocacy oriented & No focus \\
\hline $\begin{array}{l}\text { Main target fields of } \\
\text { social innovation } \\
\text { policy }\end{array}$ & $\begin{array}{c}\text { Work integration, } \\
\text { health, social } \\
\text { services }\end{array}$ & $\begin{array}{c}\text { Community development, } \\
\text { environmental sustainability }\end{array}$ & \\
Countries & $\begin{array}{l}\text { Czech Republic, } \\
\text { Denmark, Spain, } \\
\text { Sweden, The } \\
\text { United Kingdom }\end{array}$ & $\begin{array}{c}\text { The Netherlands, France, } \\
\text { Germany }\end{array}$ & Italy \\
& & & \\
& & & \\
\end{tabular}

Table 3. Suggested Outcomes of Social Innovation in Policy.

\begin{tabular}{|c|c|c|c|c|}
\hline & \multicolumn{4}{|c|}{ Focal point of expectations } \\
\hline & Unclear & One sided & Balanced & Balanced+ \\
\hline $\begin{array}{l}\text { Supposed } \\
\text { transformations/ } \\
\text { outcomes }\end{array}$ & & $\begin{array}{l}\text { Economic } \\
\text { stimulation }\end{array}$ & $\begin{array}{l}\text { Economic as well } \\
\text { as community- } \\
\text { driven objectives }\end{array}$ & $\begin{array}{l}\text { Additional focus } \\
\text { on country's } \\
\text { general innovation } \\
\text { system }\end{array}$ \\
\hline Countries & $\begin{array}{l}\text { Czech Republic, } \\
\text { Sweden }\end{array}$ & France & Denmark, Spain & $\begin{array}{c}\text { Germany, Italy, } \\
\text { The Netherlands, } \\
\text { The United } \\
\text { Kingdom }\end{array}$ \\
\hline
\end{tabular}

stimulation is also a priority for these countries. France forms a second, separate focal point in that it sees social innovation primarily as a vehicle of promoting economic development. The analyzed policy documents focused on the promotion of entrepreneurship in the social arena and other forms of economic stimulation. A third version of social innovation is found, where countries share the focus on economic development, but see social innovation as one component within "a greater national innovation system." This was clearly the most prevalent image (Germany, Italy, Netherlands, and the United Kingdom). In the Czech Republic and Sweden, in contrast to the other countries, no distinct image on social innovation could be identified. Part of the reason for the "unclear focus" is that in Sweden and the Czech Republic social innovation was hardly referred to at all explicitly in policy documents during the studied period, suggesting that in these countries social innovation is not a subject which national policymakers care about or are especially aware of, or a matter that lies within their area of responsibility.

Despite the clustering we performed, it must be stressed that the specific topics debated in the national policy documents varied substantially across countries. Although policies across countries share a general focus on economic growth and social cohesion, the practical paths to achieving these aims differ. In analyzing the 
Table 4. Prominence of Social Innovation and Relation to the Third Sector.

\begin{tabular}{lcccc}
\hline & & \multicolumn{2}{c}{ Relation of social innovation policies to the third } \\
sector
\end{tabular}

objectives of social innovation, we were able to identify organizational field transformations as central to policies in the Netherlands, the United Kingdom, and Germany. In Spain, Sweden, and Denmark, instead policies focused on the development of products, services, and processes. Equal relevance was given to the two objectives in the Czech Republic, France, and Italy. Responsibilities for meeting these expectations on the actor level were only weakly identified or addressed across all countries. Organizational traits of actors driving social innovation were not specified for instance. The only tendency that could be identified was that small and new organizations were presented as more innovative in the policy documents, in line with the EU level.

\section{Innovation Actors at the Country Level}

Despite the general vagueness on specific organizations as promoters of social innovation, we did press this issue further. One of our initial assumptions in the policy analysis was that the third sector and its organizations would be understood as particularly prone to initiating social innovation. This focus on the third sector was only confirmed for some of the countries, namely, France, Denmark, and Spain. As shown in Table 4, these were also exclusively countries where social innovation as a theme was considered of high prominence. The third sector was only ascribed a medium level of importance with regard to social innovation in Germany, the United Kingdom, and the Netherlands. Although this corresponds with a medium level of attention for the phenomenon itself in the first two, the importance of the third sector was medium in the Netherlands although attention for social innovation itself was high. In a last group of countries, the third sector had only a weak relation to social innovation. This was paired with a low level of attention for the subject in Sweden and in the Czech Republic, and a medium level in Italy. This part of the analysis does not suggest that the third sector is irrelevant for social innovation in the policy documents. It is more accurate to say that the respective policy documents were neutral to sector affiliation.

There is some variation in the indicative capacity of this classification in that some policy documents saw the third sector as more innovative in particular fields 
Table 5. Reference to EU Policies.

\begin{tabular}{|c|c|c|}
\hline $\begin{array}{l}\text { Weak reference to EU } \\
\text { policies }\end{array}$ & $\begin{array}{l}\text { Mixed reference depending on } \\
\text { subject }\end{array}$ & Strong reference to EU policies \\
\hline$\leftarrow$ & & $\rightarrow$ \\
\hline $\begin{array}{l}\text { France, The United } \\
\text { Kingdom }\end{array}$ & $\begin{array}{l}\text { Czech Republic, Denmark, } \\
\text { Italy, The Netherlands }\end{array}$ & Germany, Spain, Sweden \\
\hline
\end{tabular}

Note. EU = European Union.

or settings but not as more innovative per se. An additional factor in estimating third sector relevance is time. For example, the role of the third sector in the United Kingdom changed substantially over time from being very to less important, one case in point being the shift from a third sector to a Big Society focus and the subsequent gradual devolution of the latter (Alcock, 2016). The only really stable position of the third sector as the innovator is found in Denmark.

\section{Links Between the Country and the EU Level}

As a final perspective, lying in between the exploratory and the explanatory parts of our analysis, we looked at how strongly country policies on social innovation related to the EU level. The findings are summarized in Table 5.

Overall, the EU agenda on social innovation is of relevance for country policies. Commonalities mainly comprise similar expectations of the effects of social innovations. Explicit links to the EU level are only established in Germany, Spain, and Sweden strongly. These countries directly refer to EU policies in national strategic documents. Thus, there is considerable influence of the EU on national-level policies, but as will be seen in conjunction with the testing below the exact interpretation of social innovation differs remarkably by country.

\section{Explanatory Analysis: Proposition Testing}

In addition to the more explorative screening of the policy discourse in the first part of the analysis, we tested whether social innovation policies would comply with suggestions derived from the VoC (Hall \& Soskice, 2001). In doing so, we intended to analyze the compatibility between social innovations and the principles governing traditional innovation policy regimes. First, the countries included in the policy analysis were classified as CME, LME, or LME-like, and also hybrids according to this approach. VoC focuses on different degrees of state involvement in national economies. Following the basic assumptions and classifications by Hall and Soskice and complementing those with the extensions suggested by Schneider \& Paunescu (2012), we arrived at the classification displayed in Table 6. 
Table 6. Classification of LME and CME Countries.

\begin{tabular}{|c|c|c|c|}
\hline State(-dominated) & & & Market(-dominated) \\
\hline $\begin{array}{l}\text { Incremental and } \\
\text { technological innovation }\end{array}$ & & & $\begin{array}{l}\text { Radical and social } \\
\text { innovation }\end{array}$ \\
\hline$\leftarrow$ & & & - \\
\hline CME & Hybrids & LME-like & LME \\
\hline Germany, France & $\begin{array}{l}\text { Italy, Czech } \\
\text { Republic }\end{array}$ & $\begin{array}{l}\text { Spain, Sweden, The } \\
\text { Netherlands }\end{array}$ & $\frac{\text { Denmark, }}{\text { Kingdom }}$ \\
\hline
\end{tabular}

Source. Based on Hall and Soskice (200I) and Schneider and Paunescu (20I2).

Note. Country category affiliation indicated by different fonts: bold-CME countries, roman-hybrid countries, italics-LME-like countries, and underline-LME countries. LME = liberal market economy; CME $=$ coordinated market economy.

Table 7. Policy Focus on Types of Innovation.

Focus on technological innovation

$\leftarrow$

Germany, Italy,

The United Kingdom
The Netherlands,

Spain, Sweden,

Czech Republic
Focus on social innovation in the context of social policy

Note. Country category affiliation indicated by different fonts: bold-CME countries, roman-hybrid countries, italics - LME-like countries, and underline-LME countries. CME = coordinated market economy; LME = liberal market economy.

\section{Proposition I}

Our first proposition in relation to the VoC approach was that social innovation policies in LMEs would be subordinate to technological innovation policies, whereas CMEs would be more interested in the effects of social innovation in the context of social policy.

Table 7 presents the distribution of foci on types of innovations and their effects in the documents analyzed. The policy documents from Denmark and France display a much stronger focus on social innovation in its own right than the others. The policy documents from Germany, Italy, and the United Kingdom on the contrary are more concerned with technological developments, whereas the documents from the Netherlands, Spain, Sweden, and the Czech Republic constitute a group of countries that lies in between these two categories. Overall, we find rather mixed evidence on the proposition that LMEs would be more directed toward technological innovation, whereas CMEs would be more interested in the effects of social innovation in the context of social policy: The United Kingdom and France behave in congruence with the initial expectations while Denmark and German defy them.

\section{Propositions 2 and 3}

Our second proposition suggested that social innovation policies in CME countries would be more likely to embrace civic action than those in LME countries. This is 
Table 8. Policy Levels and Relation to Civic Action.

\begin{tabular}{|c|c|c|c|c|}
\hline & & \multicolumn{3}{|c|}{ Relation of SI policies to civic action } \\
\hline & & Weak relation & Medium relation & Strong relation \\
\hline \multirow[t]{2}{*}{ Policy level } & National & Czech Republic & Italy & $\begin{array}{l}\text { The Netherlands, } \\
\text { Denmark, The } \\
\text { United Kingdom }\end{array}$ \\
\hline & $\begin{array}{r}\text { Equal weight on } \\
\text { multiple levels }\end{array}$ & France & Sweden & Spain, Germany \\
\hline
\end{tabular}

Note. The selected policy documents in both Denmark and the United Kingdom also exhibit a focus on the local level, but it is presided over by the national focus and there is little reference to the regional level. Country category affiliation indicated by different fonts: bold-CME countries, roman-hybrid countries, italics-LME-like countries, and underline-LME countries. SI = social innovation; CME = coordinated market economy; LME = liberal market economy.

connected to our third proposition, which stated that policymakers in CMEs would be prone to discuss social innovation with a focus on multiple policy levels because the corresponding collaboration between actors from different levels matches CMEs' corporatist nature. In contrast, in LMEs we expected policies to focus more on the national level. Based on the illustration in Table 8, we can reject our second proposition because Germany is the only CME country in which civic involvement plays a pronounced role among a number of LME or LME-like countries (Denmark, the United Kingdom, Netherlands, and Spain).

The third proposition in contrast was confirmed for the most part because Denmark, the United Kingdom, and the Netherlands exhibit a strong focus on national policy, whereas the other countries, except for the hybrids, refer to multiple policy levels.

\section{Discussion and Conclusion}

In our study, we have been able to identify a largely common approach to social innovation among a group of three EU countries consisting of the United Kingdom, Denmark, and the Netherlands. The social innovation policies in these three countries form the most cohesive set of shared principles in our sample. In this common approach, a national-level policy framework is combined with the promotion of civic action. When we relate back to the exploratory analysis, this is furthermore paired with a policy authority that is distributed across several ministries. Interestingly, they share with the EU level a high prominence of the theme but interpret it in a fashion that is in rather clear contrast to the EU image of social innovation, where civic action instead is pronounced only to a medium degree, and policy authority is focused in terms of policy areas but distributed across geographic levels.

A second "group" of countries which we can make out in the material is formed by former socialist Czech Republic and the social-democratic Sweden, where social innovation is not considered a priority area, with the corresponding effects on the prominence of the theme and also the relations to civil society or the third sector, for instance. 
We can only speculate about the reasons, but it seems likely that these reasons will differ markedly across the two countries. Disregard in the Czech Republic might be motivated by the fact that the country, clearly embracing market logics in its postsocialist transition, is in a state where economic matters currently take clear priority over social issues. In Sweden, the neglect for the concept of social innovation-and possible links to civil society-is instead likely to occur more or less incrementally in the framework of a very strong and highly developed welfare state, a fact which might make the matter of explicit and "externally" driven social innovations more redundant.

France, Germany, Italy, and Spain in contrast to both the other two groups only share a trait in that their respective social innovation policies defy any kind of common classification.

Although the results of our policy analysis have revealed trends and some commonalities across the countries and also made it possible to identify groups of countries related to their national social innovation policies, these preliminary findings still need to be interpreted with caution. For example, there are no clear distinctions made in all analyzed policy documents between technological and social innovations. These differences are instead only vaguely addressed or handled, or rather dealt with by referring more generally to the idea of "innovations." This might comprise very different underlying concepts and approaches, without being clearly identified. Not least could this be a result of different employments of the term social innovation (Marques, Morgan, \& Richardson, 2017), as can, for instance, also be observed in reference to "social investment" which ranges from "social investment policy" (Owen, 1990) to an emergent field for socially minded capital investors (Nicholls, 2010). Also, results are fuzzy when it comes to the identification of the specific policy agendas regarding social innovation. Several policy areas might deal with the concept in parallel, but without systematically relating to each other, thereby merging or loosely coupling established policy traditions (an observation also made in relation to the literature on social innovation; see Ayob et al., 2016), for instance, those in social policy or technological innovation. To date, although social innovation as a cross-cutting theme is likely to enhance thematic coupling and the transgression of policy borders, the effects or the underlying intentions behind such moves are not clearly spelled out in the documents.

The exploratory and explanatory testing in combination suggests that social innovation largely defies the principles governing traditional innovation policy regimes and might necessitate new classification and prediction frameworks. Up until now, we could only identify two groups of countries that behave in a similar fashion, though the countries in one of the groups do so at least in part supposedly out of different reasons (the Czech Republic and Sweden). More in-depth research is needed to make out gradual differences across countries within one cluster, which would allow researchers to trace where specific notions come from or how they could be modified through political governance.

One of the key findings in relation to political governance is that, despite the thematic leadership of the EU on this particular subject, the trickle-down effect of EU 
agendas to national or regional policies and programs is at best incomplete and there seems still no concise or common understanding of these processes. The majority of countries do not exhibit any strong relation to the EU level. What is more, EU policies are likely an important reference point, in particular in subject-specific areas, but in the material we rarely find a national interpretation of social innovation that is wholly in line with the EU concept. Whether national variations in the interpretation of social innovation are beneficial in promoting the subject or not would need more targeted testing. In any case, it is a hint for policymakers that systemization might be needed.

The need for such systemization is pushed further by our finding that both EU and national agendas on social innovation are still rather vague in many regards. Social innovation is promoted as apt to "solve societal problems," but the details are unclear and little or no attention is paid to the actual actors that are supposed to bring about the wanted solutions. More research and policy discussion are needed to form a more cogent idea of who the innovators are supposed to be and from that point of departure how they can be supported. The lack of such an understanding might result in severe redundancies, coordinative disorders, overlapping competencies, and imperfect allocations. By instead developing a clearer and more precise image of these actors and their processes, not only the strengths and weaknesses of a country's innovative capacity might be identified. It could also provide policymakers and others with important insights for developing a more coherent policy framework for the promotion of social innovation.

\section{Declaration of Conflicting Interests}

The author(s) declared no potential conflicts of interest with respect to the research, authorship, and/or publication of this article.

\section{Funding}

The author(s) disclosed receipt of the following financial support for the research, authorship, and/or publication of this article: This study has received funding from the European Commission within the ITSSOIN project (613177).

\section{Notes}

1. See Ebner (2010) on differences in between LMEs and CMEs in competitive standardization of industry standards, or industrial relations including wage setting; see also Thelen and Kume (2006) with a focus on CMEs.

2. See Koos (2011) on the positive effect on firms' civic engagement where welfare institutions and corporatist structures are pronounced at the same time.

3. Other European projects have examined policies relevant to the social economy and/or social innovation, among which are tepsie, wilco, effeseis, tsi, cressi, simpact, and SI-drive. However, they have either applied different methods or focused on different countries and research questions. So none of the other investigations we are aware of has produced findings that contradict our own. The projects' outputs might, however, be consulted for complementary perspectives. 


\section{References}

Alcock, P. (2016). From partnership to the big society: The third sector policy regime in the UK. Nonprofit Policy Forum, 7, 95-116. doi:10.1515/npf-2015-0022

Anheier, H. K., Krlev, G., Preuss, S., Mildenberger, G., Einarsson, T., \& Flening, E. (2015). Social innovation in policy. EU and country level profiles and policy perspectives (A deliverable of the project: "Impact of the Third Sector as Social Innovation" (ITSSOIN), European Commission-7th Framework Programme). Brussels, Belgium: DG Research, European Commission.

Asheim, B. T., Lawon Smith, H., \& Oughton, C. (2011). Regional innovation systems: Theory, empirics and policy. Regional Studies, 45, 875-891.

Atkinson, R., Terizakis, G., \& Zimmermann, K. (Eds.). (2010). Routledge Advances in European Politics: Vol. 68. Sustainability in European environmental policy: Challenges of governance and knowledge. London, England: Routledge.

Ayob, N., Teasdale, S., \& Fagan, K. (2016). How social innovation "came to be": Tracing the evolution of a contested concept. Journal of Social Policy, 45, 635-653. doi:10.1017/ S004727941600009X

Baglioni, S., \& Sinclair, S. P. (2018). Social innovation and social policy: Theory, policymaking and practice (1st ed.). Bristol, UK: Policy Press.

Balme, R., \& Ye, Q. (2014). Multi-level governance and the environment: Intergovernmental relations and innovation in environmental policy. Environmental Policy and Governance, 24, 147-154. doi:10.1002/eet.1635

Baumgartner, F. R. (2014). Ideas, paradigms and confusions. Journal of European Public Policy, 21, 475-480. doi:10.1080/13501763.2013.876180

Béland, D. (2009). Ideas, institutions, and policy change. Journal of European Public Policy, 16, 701-718. doi:10.1080/13501760902983382

Béland, D. (2016). Ideas and institutions in social policy research. Social Policy \& Administration, 50, 734-750. doi:10.1111/spol.12258

Bogers, M., Chesbrough, H., \& Moedas, C. (2018). Open innovation: Research, practices, and policies. California Management Review, 60, 5-16. doi:10.1177/0008125617745086

Bozeman, B. (2013). What organization theorists and public policy researchers can learn from one another: Publicness theory as a case-in-point. Organization Studies, 34, 169-188. doi: $10.1177 / 0170840612473549$

Bryson, J. M. (2018). Bryson on Strategic Planning. Strategic planning for public and nonprofit organizations: A guide to strengthening and sustaining organizational achievement (5th ed.). Hoboken, NJ: Wiley.

Casadella, V., \& Uzunidis, D. (2017). National innovation systems of the south, innovation and economic development policies: A multidimensional approach. Journal of Innovation Economics, 23, 137-157. doi:10.3917/jie.pr1.0007

Crosby, B. C., 't Hart, P., \& Torfing, J. (2016). Public value creation through collaborative innovation. Public Management Review, 19, 655-669. doi:10.1080/14719037.2016.1192165

Daigneault, P.-M. (2014). Reassessing the concept of policy paradigm: Aligning ontology and methodology in policy studies. Journal of European Public Policy, 21, 453-469. doi:10.10 80/13501763.2013.834071

Dax, T., \& Fischer, M. (2017). An alternative policy approach to rural development in regions facing population decline. European Planning Studies, 26, 297-315. doi:10.1080/0965431 3.2017 .1361596 
Despard, M. R. (2016). Can nonprofit capacity be measured? Nonprofit and Voluntary Sector Quarterly, 46, 607-626. doi:10.1177/0899764016661425

Dunmire, P. L. (2012). Political discourse analysis: Exploring the language of politics and the politics of language. Language and Linguistics Compass, 11, 735-751.

Ebner, A. (2010). Varieties of capitalism and the limits of entrepreneurship policy: Institutional reform in Germany's coordinated market economy. Journal of Industry, Competition and Trade, 10, 319-341. doi:10.1007/s10842-010-0086-x

Edmiston, D. (2015). EU public policy, social innovation and marginalisation: Reconciling ambitions with policy instruments (Part of deliverable 6.1 of the CRESSI research programme, CRESSI Working Papers No. 18/2015). Retrieved from http://eureka.sbs.ox.ac. uk/5949/

Enjolras, B. (2009). Between market and civic governance regimes: Civicness in the governance of social services in Europe. VOLUNTAS: International Journal of Voluntary and Nonprofit Organizations, 20, 274-290. doi:10.1007/s11266-009-9091-2

European Commission. (2013). Guide to social innovation. Retrieved from http://ec.europa.eu/ regional_policy/sources/docgener/presenta/social_innovation/social_innovation_2013.pdf

Fligstein, N. (2006). Sense making and the emergence of a new form of market governance: The case of the European defense industry. American Behavioral Scientist, 49, 949-960.

Fotaki, M. (2010). Why do public policies fail so often? Exploring health policy-making as an imaginary and symbolic construction. Organization, 17, 703-720. doi:10.1177 $/ 1350508410366321$

Fougère, M., Segercrantz, B., \& Seeck, H. (2017). A critical reading of the European Union's social innovation policy discourse: (Re)legitimizing neoliberalism. Organization, 24, 819843. doi:10.1177/1350508416685171

Haß, R., \& Serrano-Velarde, K. (2015). When doing good becomes a state affair: Voluntary service in Germany. VOLUNTAS: International Journal of Voluntary and Nonprofit Organizations, 26, 1718-1738. doi:10.1007/s11266-015-9577-z

Hajer, M. (2003). Policy without polity? Policy analysis and the institutional void. Policy Sciences, 36, 175-195. doi:10.1023/A:1024834510939

Hall, P. A., \& Soskice, D. W. (Eds.). (2001). Varieties of capitalism: The institutional foundations of comparative advantage. Oxford, UK: Oxford University Press.

He, Z. (2016). Local government innovation and revealed ideas of political legitimacy: A comparative study between the United States and China. Journal of Chinese Political Science, 21, 1-19. doi:10.1007/s11366-015-9376-9

Henriksen, L. S., Smith, S. R., \& Zimmer, A. (2012). At the eve of convergence? Transformations of social service provision in Denmark, Germany, and the United States. VOLUNTAS: International Journal of Voluntary and Nonprofit Organizations, 23, 458-501. doi:10.1007/ s11266-011-9221-5

Hewitt, S. (2009). Discourse analysis and public policy research (Centre for Rural Economy Discussion Paper Series No. 24). Retrieved from http://www.ncl.ac.uk/media/wwwnclacuk/centreforruraleconomy/files/discussion-paper-24.pdf

Höpner, M., \& Schäfer, A. (2012). Integration among unequals: How the heterogeneity of European varieties of capitalism shapes the social and democratic potential of the EU (MPIfG Discussion Paper 12/5). Retrieved from http://www.mpifg.de/pu/dp_abstracts/ dp12-5.asp 
Howarth, D. R., \& Torfing, J. (2005). Discourse theory in European politics: Identity, policy, and governance. Basingstoke, UK: Palgrave Macmillan.

Jett, C., \& Vaillancourt, Y. (2011). Social economy and home care services in Quebec: Co-production or co-construction? VOLUNTAS: International Journal of Voluntary and Nonprofit Organizations, 22, 48-69. doi:10.1007/s11266-010-9134-8

John, P. (2003). Is there life after policy streams, advocacy coalitions, and punctuations: Using evolutionary theory to explain policy change? Policy Studies Journal, 31, 481-498. doi:10.1111/1541-0072.00039

Kendall, J. (Ed.). (2009). Handbook on third sector policy in Europe: Multi-level processes and organized civil society. Cheltenham, UK: Edward Elgar.

Kim, M. (2016). Characteristics of civically engaged nonprofit arts organizations. Nonprofit and Voluntary Sector Quarterly, 46, 175-198. doi:10.1177/0899764016646473

Kingdon, J. W. (1995). Agendas, alternatives, and public policies (2nd ed.). New York, NY: Harper Collins College.

Koos, S. (2011). The institutional embeddedness of social responsibility: A multilevel analysis of smaller firms' civic engagement in Western Europe. Socio-economic Review, 10, 135162. doi:10.1093/ser/mwr027

Krlev, G., Bund, E., \& Mildenberger, G. (2014). Measuring what matters-Indicators of social innovativeness on the national level. Information Systems Management, 31, 200-224. doi:1 $0.1080 / 10580530.2014 .923265$

Kuhlmann, S., \& Rip, A. (2018). Next-generation innovation policy and grand challenges. Science and Public Policy, 45, 448-454. doi:10.1093/scipol/scy011

Lacomba, J., Boni, A., Cloquell, A., \& Soledad, C. (2015). Immigrant associations and codevelopment policies: Among the opportunities for strengthening and the risks of cooptation in the case of Valencia region (Spain). VOLUNTAS: International Journal of Voluntary and Nonprofit Organizations, 26 1852-1873. doi:10.1007/s11266-014-9491-9

Lurtz, K., \& Kreutzer, K. (2017). Entrepreneurial orientation and social venture creation in nonprofit organizations. Nonprofit and Voluntary Sector Quarterly, 46, 92-115. doi:10.1177/0899764016654221

Marques, P., Morgan, K., \& Richardson, R. (2017). Social innovation in question: The theoretical and practical implications of a contested concept. Environment and Planning C: Politics and Space, 36, 496-512.

Mayring, P. (2007). Qualitative Inhaltsanalyse [Qualitative Content Analysis] (9th ed.). Weinheim, Germany: Beltz.

Mazzucato, M. (2018). Missions: Mission-oriented research \& innovation in the European Union: A problem-solving approach to fuel innovation-led growth. Luxembourg City, Luxembourg: Publications Office of the European Union.

Messeghem, K., Bakkali, C., Sammut, S., \& Swalhi, A. (2018). Measuring nonprofit incubator performance: Toward an adapted balanced scorecard approach. Journal of Small Business Management, 56, 658-680. doi:10.1111/jsbm.12317

Milbourne, L., \& Cushman, M. (2013). From the third sector to the big society: How changing UK government policies have eroded third sector trust. VOLUNTAS: International Journal of Voluntary and Nonprofit Organizations, 24, 485-508. doi:10.1007/s11266-012-9302-0

Nicholls, A. (2010). The institutionalization of social investment: The interplay of investment logics and investor rationalities. Journal of Social Entrepreneurship, 1, 70-100.

Nicholls, A. (2013). The social entrepreneurship-social policy nexus in developing countries. In R. Surender \& R. Walker (Eds.), Social policy in a developing world (pp. 183-216). Cheltenham, UK: Edward Elgar. 
North, D. C. (1990). Institutions, institutional change and economic performance. Cambridge, UK: Cambridge University Press.

Osborne, S. P. (2013). Routledge studies in the management of voluntary and non-profit organizations. Voluntary organizations and innovation in public services. London, England: Routledge.

Owen, D. L. (1990). Towards a theory of social investment: A review essay. Accounting, Organizations and Society, 15, 249-265. doi:10.1016/0361-3682(90)90007-H

Pol, E., \& Ville, S. (2009). Social innovation: Buzz word or enduring term? The Journal of Socio-economics, 38, 878-885.

Prange, H. (2008). Explaining varieties of regional innovation policies in Europe. European Urban and Regional Studies, 15, 39-52. doi:10.1177/0969776407081276

Ramstad, E. (2009). Expanding innovation system and policy: An organisational perspective. Policy Studies, 30, 533-553.

Rao-Nicholson, R., Vorley, T., \& Khan, Z. (2017). Social innovation in emerging economies: A national systems of innovation based approach. Technological Forecasting and Social Change, 121, 228-237. doi:10.1016/j.techfore.2017.03.013

Reuter, M., Wijkström, F., \& von Essen, J. (2012). Policy tools or mirrors of politics: Government-voluntary sector compacts in the post-welfare state age. Nonprofit Policy Forum, 3(2). doi:10.1515/2154-3348.1062

Rogers, E., \& Dearing, J. (1988). Agenda-setting research: Where has it been, where is it going? In J. A. Anderson (Ed.), Communication yearbook (11th ed., pp. 555-594). Beverly Hills, CA: SAGE.

Sabatier, P. A., \& Jenkins-Smith, H. C. (Eds.). (1993). Theoretical lenses on public policy. Policy change and learning: An advocacy coalition approach. Boulder, CO: Westview Press.

Schneider, M., \& Paunescu, M. (2012). Changing varieties of capitalism and revealed comparative advantages from 1990 to 2005: A test of the Hall and Soskice claims. Socio-economic Review, 10, 731-753.

Schot, J., \& Steinmueller, W. E. (2018). Three frames for innovation policy: R\&D, systems of innovation and transformative change. Research Policy, 47, 1554-1567. doi:10.1016/j. respol.2018.08.011

Schreier, M. (2013). Qualitative content analysis in practice (Reprinted). Los Angeles, CA: SAGE.

Sinclair, S., \& Baglioni, S. (2014). Social innovation and social policy? Promises and risks. Social Policy and Society, 13, 469-476. doi:10.1017/S1474746414000086

Sinclair, S., Mazzei, M., Baglioni, S., \& Roy, M. J. (2018). Social innovation, social enterprise, and local public services: Undertaking transformation? Social Policy \& Administration, 52, 1317-1331. doi:10.1111/spol.12389

Stier, S. (2015). Political determinants of e-government performance revisited: Comparing democracies and autocracies. Government Information Quarterly, 32, 270-278. doi:10.1016/j.giq.2015.05.004

Stone, M. M., \& Sandfort, J. R. (2009). Building a policy fields framework to inform research on nonprofit organizations. Nonprofit and Voluntary Sector Quarterly, 38, 1054-1075. doi:10.1177/0899764008327198

Terstriep, J., \& Totterdill, P. (2014, October 16-17). Economic foundation of social innovation: New modes of policy production. Working paper for RIP 2014-9th Regional Innovation 
Policies Conference, University of Stavanger, Stavanger, Norway. Retrieved from http:// www.simpact-project.eu/publications/scientific/Terstriep_Totterdill_RIP2014.pdf

The Young Foundation. (2012). Social innovation overview: Part I-Defining social innovation (A deliverable to the project "The Theoretical, Empirical and Policy Foundations for Building Social Innovation in Europe”). Brussels, Belgium: European Commission, DG Research.

Thelen, K., \& Kume, I. (2006). Coordination as a political problem in coordinated market economies. Governance, 19, 11-42. doi:10.1111/j.1468-0491.2006.00302.x

Thøgersen, M. (2015). Explaining collaboration and commitment in Danish non-profit organizations: Linking institutional environments to outcomes. VOLUNTAS: International Journal of Voluntary and Nonprofit Organizations, 26, 1639-1665. doi:10.1007/s11266015-9604-0

Vaara, E., Sorsa, V., \& Palli, P. (2010). On the force potential of strategy texts: A critical discourse analysis of a strategic plan and its power effects in a city organization. Organization, 17, 685-702. doi:10.1177/1350508410367326

Walgrave, S., \& van Aelst, P. (2006). The contingency of the mass media's political agenda setting power: Toward a preliminary theory. Journal of Communication, 56, 88-109. doi:10.1111/j.1460-2466.2006.00005.x

Wen, Z., \& Chong, A. M. L. (2014). Legitimate deficit: Competitive bidding in a residual and semi-democratic welfare society. VOLUNTAS: International Journal of Voluntary and Nonprofit Organizations, 25, 1214-1234. doi:10.1007/s11266-014-9499-1

Yanow, D. (1996). How does a policy mean? Interpreting policy and organizational actions. Washington, DC: Georgetown University Press.

Yanow, D. (2009). Qualitative Research Methods Series: Vol. 47. Conducting interpretive policy analysis. Thousand Oaks, CA: SAGE.

\section{Author Biographies}

Gorgi Krlev is a research associate at the Centre for Social Investment at the University of Heidelberg. He holds a DPhil in business and management from the University of Oxford (Kellogg College). Currently, his main research subjects are organizational hybridity, social innovation, and impact.

Torbjörn Einarsson holds a doctorate in business administration and management at Stockholm Center for Civil Society Studies, Stockholm School of Economics. His research covers ongoing and historical changes in the Swedish civil society as well as membership and governance in membership-based organizations.

Filip Wijkström is associate professor at the Stockholm School of Economics and the center director at Stockholm Center for Civil Society Studies. His research spans from civil society governance to the development and significance of civil society organizations in society.

Lea Heyer holds a PhD scholarship in social pedagogy and organization studies at Hildesheim University. Her research takes on a social networks perspective on multiprofessional cooperation in working with youth and religion.

Georg Mildenberger is head of research at the Centre for Social Investment at the University of Heidelberg. He has led several project teams working on social innovation in the European context and in addition to this has focused on researching social investment, impact measurement, and volunteering. 